\title{
HAK ATAS KEKAYAAN INTELEKTUAL DALAM DUNIA TEKNOLOGI SAMSUNG
}

\author{
Erika Stacia Marsailis \\ 155100026, 785567901 \\ Fakultas Komputer \\ erikastaciamarailis.student@umitra.ac.id
}

\begin{abstract}
Samsung Android merupakan jenis smartphone berbasis Android yang diproduksikan oleh PT. Samsung Electronic, yang menjadi produk paling diminati dipasaran pada dewasa ini. Pada quartal pertama tahun 2013, penjualan smartphone Samsung Android menduduki posisi pertama untuk kategori smartphone dengan tingkat penjualan mencapai 32,7\%. Penelitian ini dilakukan terhadap 100 orang responden yang mengunjungi pusat penjualan handphone di Bandung Electronic Center (BEC). Tujuan dari penelitian ini adalah untuk mengetahui sub variabel manakah dari atribut produk yang memiliki pengaruh paling dominan terhadap keputusan pembelian dan seberapa besar pengaruh atribut produk terhadap keputusan pembelian.

Atribut produk adalah unsur-unsur produk yang dipandang penting oleh konsumen dan dijadikan dasar pengambilan keputusan pembelian (Tjiptono, 2008:103). Kualitas produk, fitur produk, gaya dan desain produk, merek, dan layanan pendukung, merupakan unsur-unsur dari atribut produk yang digunakan untuk sub variabel independen pada penelitian ini. Keputusan pembelian konsumen adalah membeli merek yang paling disukai (Kotler \& Amstrong, 2008:181). Terdapat 6 unsur yang menjadi perhatian dan pertimbangan konsumen dalam membuat keputusan pembelian yaitu, pilihan produk, pilihan merek, pilihan penyalur, waktu pembelian, jumlah pembelian, dan metode pembayaran. Penelitian ini menggunakan metode kuantitatif dengan jenis penelitian deskriptif dan kausal. Jumlah populasi pada penelitian ini tidak diketahui, teknik pengambilan sampling yang digunakan adalah non probability sampling dengan $\mathrm{j}$ enis insidental sampling. Teknik analisis yang digunakan yaitu, analisis statistik deskriptif, Method of Successive Interval (MSI), uji asumsi klasik (uji normalitas, uji multikolinieritas, uji heteroskedastisitas, uji linieritas), uji regresi linier berganda, uji korelasi, uji t, uji F dan koefisien determinasi.
\end{abstract}

Kata kunci: Atribut produk (Kualitas produk, Fitur produk, Gaya dan desain produk, Merek, Layanan pendukung), Keputusan pembelian. 


\section{A. INTRODUCTION}

Seiring laju ekspansinya yang terus berlanjut di pasar smartphone dan tablet, dan di tengah memanasnya sengketa dengan Samsung baru saja mengambil langkah besar dengan menanda-tangani suatu kesepakatan dengan Microsoft terkait paten-paten yang dimiliki oleh kedua perusahaan. Dengan demikian keduanya akan saling melisensikan kepada satu sama lain paten-paten milik masingmasing yang tercakup dalam kesepakatan ini, dimana Samsung juga setuju untuk bekerja-sama dengan Microsoft untuk mengembangkan perangkat-perangkat baru ponsel yang berbasis sistem operasi Windows.

Namun tentunya substansi yang paling mencuri perhatian banyak kalangan dari kesepakatan ini adalah Samsung akan membayar royalti kepada Microsoft untuk setiap perangkat berbasis Android yang berhasil mereka jual. Diraihnya kesepakatan ini dapat disebut sebagai bagian dari suksesnya kampanye besar-besaran yang dilakukan Microsoft belakangan ini untuk mengikat para produsen perangkat yang menggunakan sistem operasi Android dengan perjanjian lisensi untuk patenpaten terkait milik Microsoft, sehingga menghindarkan produsen-produsen tersebut dari gugatan pelanggaran paten.

Perjanjian lisensi yang mereka tanda-tangani dengan HTC tahun lalu setidaknya membuat perusahaan yang didirikan oleh Bill Gates itu kini panen royalti dari dua perusahaan yang menguasai lebih dari setengah dari pasar ponsel Android di Amerika Serikat. Ini belum termasuk sejumlah produsen lain baik untuk ponsel maupun tablet seperti Acer, General Dynamics Itronix, Onkyo, Velocity Micro, ViewSonic dan Winstron yang juga telah mencapai kesepakatan dengan Microsoft dalam tiga bulan terakhir ini.

Meskipun sistem operasi Android sendiri dikembangkan oleh Open Handset Alliance yang dipimpin oleh Google dan dirilis sebagai perangkat lunak yang kepemilikannya terbuka dan bebas, namun banyak pihak yang menuding bahwa sistem operasi tersebut berikut pengembangannya lebih lanjut telah melanggar sejumlah paten milik pihak lain. Pada bulan Agustus 2010 contohnya, perusahaan IT raksasa Oracle yang saat itu belum lama mengakuisisi Sun Microsystems mengajukan gugatan terhadap Google atas tuduhan pelanggaran terhadap 
paten-paten atas bahasa pemograman Java yang terjadi dalam pengembangan yang dilakukan oleh Google atas sistem operasi Android.

Microsoft sendiri juga tentunya tak mau ketinggalan dan sejak tahun 2010 mulai meminta agar para produsen perangkat keras yang menggunakan Android membayar lisensi kepada mereka dengan klaim bahwa sistem operasi Android melanggar sejumlah paten yang mereka miliki. Klaim yang dilakukan Microsoft ini rupanya cukup berhasil, terbukti dari disepakati serangkaian perjanjian lisensi seperti yang disebutkan di atas. Sejumlah pengamat bahkan memperkirakan kalau Microsoft menghasilkan uang dengan memanfaatkan isu paten ini lima kali lipat lebih banyak dibandingkan penghasilan dari penjualan Windows 7 yang jelas-jelas merupakan sistem operasi buatan mereka sendiri.

Keberhasilan Microsoft dalam kampanyenya yang satu ini di sisi lain berarti juga menambah lagi pukulan keras untuk Google yang memang sudah sejak lama gusar dengan praktik-praktik "patentbullying" yang dilakukan oleh para kompetitornya tersebut. Kegusaran Google tampaknya semakin menjadi ketika perusahaan yang besar sebagai penyedia jasa mesin pencari di internet ini kalah bertarung dalam pelelangan paten-paten milik Nortel yang mau bangkrut pada bulan Juli lalu. Kala itu, tawaran Google senilai 900 juta dolar kandas oleh penawaran yang dilakukan oleh sebuah konsorsium yang beranggotakan - antara lain Microsoft, Apple dan RIM senilai 4,5 milyar dolar, yang langsung menutup buku pengalihan aset-aset HKI untuk teknologi mulai dari jaringan nirkabel 3G dan 4G hingga semikonduktor tersebut. Apalagi konsorsium serupa yang beranggotakan Microsoft, Apple, EMC dan Oracle juga belum lama sukses mengambilalih 882 paten milik Novell.

Google memang banyak menerima pujian karena langkah mereka mempelopori peluncuran sistem operasi Android, yang menurut Canalys berhasil merebut posisi puncak di pangsa pasar perangkat lunak untuk ponsel pintar di tahun 2010, jauh mengungguli Apple OS sekaligus menumbangkan Symbian. Namun di sisi lain Google juga banyak dikritik karena dinilai memiliki posisi tawar yang lemah di antara para kompetitornya. Pasalnya, Google tidak memiliki pegangan terhadap perangkat keras yang dapat diandalkan, dan di samping itu Google tidak banyak memiliki akses terhadap paten-paten dalam teknologi ponsel pintar. 
Padahal, dalam satu perangkat ponsel pintar saja dapat diklaim hingga sekitar 250000 paten.

Perusahaan yang bermarkas di Menlo Park, California itu kini berusaha mengejar ketertinggalannya dengan mengakuisisi Motorola Mobility pada bulan Agustus 2011 yang lalu dengan nilai transaksi sebesar 12,5 milyar dolar. Transaksi itu setidaknya memberi Google akses yang diperlukan baik terhadap pabrikan perangkat keras yang andal, dan yang lebih penting lagi akses terhadap lebih dari 17000 paten serta 7000 permohonan paten atas nama Motorola.

\section{B. CONTENT}

Sebelum tahun 1997, Samsung lebih dikenal dengan reputasinya sebagai perusahan pembuat peralatan elektronik dengan produk-produk lowend. perusahaan yang didirikan oleh Bill Gates itu kini panen royalty. Perusahaan tersebut hanya dikenal sebagai imitator, bukan innovator karena memang tidak melakukan inosai-inovasi produk pada saat itu. Produk-produk kompetitif berdasar pada low cost yang direfleksikan dengan tenaga kerja yang murah. Samsung belum mempunyai brand value dan belum memiliki pasar internasional. Strategi yang dilakukannya pada saat itu adalah cost/ price leadership.
Ketika terjadi krisis ekonomi di Asia, Samsung mengalami kerugian yang besar, namun dia dapat merespon dengan sangat baik. Ia mengembangkan turnaround strategy, meskipun masih membawa kebudayaan tua Korea Inc yang tidak fleksibel. Samsung memperbaiki kualitas dan melakukan inovasi-inovasi produk.

Samsung berfokus pada pasarpasar tertentu, ia memilih fokus pada pasar dengan permintaan terbesar, pasar Amerika yang perkembangannya tinggi, juga pada pasar yang pertumbuhannya cepat, yaitu China.

Yun Jong Yong, CEO Samsung, menggunakan cara tradisional untuk memperbaiki keadaan ekonomi Samsung pada saat itu. Ia memotong $30 \%$ biaya dalam 5 bulan. Untuk itu ia memberhentikan 30.000 dari 70.000 karyawan. Dan Juga membuang unit-unit yang tidak bermanfaat. Prestasi terbesar Yun adalah perubahan ke arah corporate culture. Samsung kemudian berkembang menjadi perusahaan berskala internasional. Dimulai dari menyewa staf yang berpendidikan Amerika atau berpengalaman secara signifikan di USA. Tiga warga yang bukan berasal dari Korea Selatan menjadi anggota komisi direktur. Warga asing 
memiliki $60 \%$ saham dari grup.

Perusahaan sekarang menghasilkan $70 \%$ dari pendapatannya di luar Korea Selatan, manufaktur di 14 negara, termasuk China dan Meksiko.

Samsung juga mengadakan partnership dengan American. Pada awal tahun 1997, Samsung hampir tidak berbisnis mobile phones di luar Korea Selatan, tapi kemudian setelah mengadakan partnership, Samsung memperoleh pesanan 1.8 juta handsets senilai $\$ 600$ juta dari Sprint PCS Group. Reputasi Samsung sekarang adalah highend mobile handsets dan berkembang sebagai supplier pada industri ini.

Setelah mengadakan partnership dengan beberapa perusahaan ternama seperti Best Buy, Radio Shack, dan Circuit City, Samsunglebih sukses dari tahun-tahun sebelumnya. Pada tahun 2001 Samsung menjual produkproduk senilai $\$ 500$, dan menargetkan penjualan $\$ 1$ miliyar di tahun 2002. penjualan terbaiknya adalah DVD/VCR player dan mobile phone dan juga PDA. Salah satu kunci sukses Samsung terletak pada desain. Teknologi dan desain pada Samsung sangat baik. Samsung memiliki 300 desainer bertalenta di Seoul dan empat kamtor desain di USA, Eropa, dan Jepang.
Penekanan produknya adalah pada gaya, best practice, simple, dan respon yang cepat pada perubahan-perubahan pasar.

Sebelum tahun 1997, Samsung lebih dikenal dengan reputasinya sebagai perusahan pembuat peralatan elektronik dengan produk-produk lowend. Perusahaan tersebut hanya dikenal sebagai imitator, bukan innovator karena memang tidak melakukan inosai-inovasi produk pada saat itu. Produkproduk kompetitif berdasar pada low cost yang direfleksikan dengan tenaga kerja yang murah. Samsung belum mempunyai brand value dan belum memiliki pasar internasional. Strategi yang dilakukannya pada saat itu adalah cost/ price leadership. Ketika terjadi krisis ekonomi di Asia, Samsung mengalami kerugian yang besar, namun dia dapat merespon dengan sangat baik. Ia mengembangkan turnaround strategy, meskipun masih membawa kebudayaan tua Korea Inc yang tidak fleksibel. Samsung memperbaiki kualitas dan melakukan inovasi-inovasi produk.

Samsung berfokus pada pasarpasar tertentu, ia memilih fokus pada pasar dengan permintaan terbesar, pasar Amerika yang perkembangannya tinggi, juga pada pasar yang 
pertumbuhannya cepat, yaitu China.

Yun Jong Yong, CEO Samsung, menggunakan cara tradisional untuk memperbaiki keadaan ekonomi Samsung pada saat itu. Ia memotong $30 \%$ biaya dalam 5 bulan. Untuk itu ia memberhentikan 30.000 dari 70.000 karyawan. Dan Juga membuang unit-unit yang tidak bermanfaat. Prestasi terbesar Yun adalah perubahan ke arah corporate culture.

\begin{tabular}{llr}
$\begin{array}{l}\text { Samsung } \\
\text { berkembang }\end{array}$ & $\begin{array}{r}\text { kemudian } \\
\text { menjadi } \\
\text { perusahaan }\end{array}$ & \multicolumn{2}{r}{ berskala } \\
internasional. & Dimulai & dari \\
menyewa & staf & yang \\
berpendidikan & Amerika $\begin{array}{r}\text { atau } \\
\text { berpengalaman }\end{array}$ & secara
\end{tabular} signifikan di USA. Tiga warga yang bukan berasal dari Korea Selatan menjadi anggota komisi direktur. Warga asing memiliki $60 \%$ saham dari grup. Perusahaan sekarang menghasilkan $70 \%$ dari pendapatannya di luar Korea Selatan, manufaktur di 14 negara, termasuk China dan Meksiko. Samsung juga mengadakan partnership dengan American. Pada awal tahun 1997, Samsung hampir tidak berbisnis mobile phones di luar Korea Selatan, tapi kemudian setelah mengadakan partnership, Samsung memperoleh pesanan 1.8 juta handsets senilai $\$ 600$ juta dari Sprint PCS Group. Reputasi Samsung sekarang adalah high- end mobile handsets dan berkembang sebagai supplier pada industri ini.

\section{CONCLUSION}

Samsung Android merupakan jenis smartphone berbasis Android yang diproduksikan oleh PT. Samsung Electronic, yang menjadi produk paling diminati dipasaran pada dewasa ini. Pada quartal pertama tahun 2013, penjualan smartphone Samsung Android menduduki posisi pertama untuk kategori smartphone dengan tingkat penjualan mencapai $32,7 \%$. Penelitian ini dilakukan terhadap 100 orang responden yang mengunjungi pusat penjualan handphone di Bandung Electronic Center (BEC). Tujuan dari penelitian ini adalah untuk mengetahui sub variabel manakah dari atribut produk yang memiliki pengaruh paling dominan terhadap keputusan pembelian dan seberapa besar pengaruh atribut produk terhadap keputusan pembelian. Atribut produk adalah unsur-unsur produk yang dipandang penting oleh konsumen dan dijadikan dasar pengambilan keputusan pembelian (Tjiptono, 2008:103). Kualitas produk, fitur produk, gaya dan desain produk, merek, dan layanan pendukung, merupakan unsurunsur dari atribut produk yang digunakan untuk sub variabel independen pada penelitian ini. Keputusan pembelian 
konsumen adalah membeli merek yang paling disukai (Kotler \& Amstrong, 2008:181). Terdapat 6 unsur yang menjadi perhatian dan pertimbangan konsumen

dalam membuat keputusan pembelian yaitu, pilihan produk, pilihan merek, pilihan penyalur, waktu pembelian, jumlah pembelian, dan metode pembayaran. Penelitian ini menggunakan metode kuantitatif dengan jenis penelitian deskriptif dan kausal. Jumlah populasi pada penelitian ini tidak diketahui, teknik pengambilan sampling yang digunakan adalah non probability sampling dengan jenis insidental sampling. Teknik analisis yang digunakan yaitu, analisis statistic deskriptif, Method of Successive Interval (MSI), uji asumsi klasik (uji normalitas, uji multikolinieritas, uji heteroskedastisitas, uji linieritas), uji regresi linier berganda, uji korelasi, uji t, uji $\mathrm{F}$ dan koefisien determinasi.

\section{DISCUSSION}

Samsung Android merupakan jenis smartphone berbasis Android yang diproduksikan oleh PT. Samsung Electronic, yang menjadi produk paling diminati dipasaran pada dewasa ini. Pada quartal pertama tahun 2013, penjualan smartphone Samsung Android menduduki posisi pertama untuk kategori smartphone dengan tingkat penjualan mencapai $32,7 \%$. Penelitian ini dilakukan terhadap 100 orang responden yang mengunjungi pusat penjualan handphone di Bandung Electronic Center (BEC). Tujuan dari penelitian ini adalah untuk mengetahui sub variabel manakah dari atribut produk yang memiliki pengaruh paling dominan terhadap keputusan pembelian dan seberapa besar pengaruh atribut produk terhadap keputusan pembelian.

Atribut produk adalah unsurunsur produk yang dipandang penting oleh

konsumen dan dijadikan dasar pengambilan keputusan pembelian (Tjiptono,

2008:103). Kualitas produk, fitur produk, gaya dan desain produk, merek, dan

layanan pendukung, merupakan unsurunsur dari atribut produk yang digunakan

untuk sub variabel independen pada penelitian ini. Keputusan pembelian konsumen adalah membeli merek yang paling disukai (Kotler \& Amstrong, 2008:181). Terdapat 6 unsur yang menjadi perhatian dan pertimbangan konsumen

dalam membuat keputusan pembelian yaitu, pilihan produk, pilihan merek, pilihan penyalur, waktu pembelian, jumlah pembelian, dan metode pembayaran.

Penelitian ini menggunakan metode kuantitatif dengan jenis penelitian deskriptif dan kausal. Jumlah populasi pada penelitian ini tidak diketahui, teknik 
pengambilan sampling yang digunakan adalah non probability sampling dengan $\mathrm{j}$

enis insidental sampling. Teknik analisis yang digunakan yaitu, analisis statistik

deskriptif, Method of Successive Interval (MSI), uji asumsi klasik (uji normalitas,

uji multikolinieritas, uji heteroskedastisitas, uji linieritas), uji regresi linier

berganda, uji korelasi, uji t, uji $\mathrm{F}$ dan koefisien determinasi.

\section{E. REFERENCE}

[1] O. M. Febriani and A. S. Putra, "Sistem Informasi Monitoring Inventori Barang Pada Balai Riset Standardisasi Industri Bandar Lampung," J. Inform., vol. 13, no. 1, pp. 90-98, 2014.

[2] A. S. Putra, "Paperplain: Execution Fundamental Create Application With Borland Delphi 7.0 University Of Mitra Indonesia," 2018.

[3] A. S. Putra, "2018 Artikel Struktur Data, Audit Dan Jaringan Komputer," 2018.

[4] A. S. Putra, "ALIAS MANAGER USED IN DATABASE DESKTOP STUDI CASE DB DEMOS."

[5] A. S. Putra, "COMPREHENSIVE SET OF PROFESSIONAL FOR DISTRIBUTE COMPUTING."

[6] A. S. Putra, "DATA ORIENTED RECOGNITION IN BORLAND DELPHI 7.0.”
[7] A. S. Putra, "EMBARCADERO DELPHI XE 2 IN GPUPOWERED FIREMONKEY APPLICATION."

[8] A. S. Putra, "HAK ATAS KEKAYAAN INTELEKTUAL DALAM DUNIA TEKNOLOGY BERBASIS REVOLUSI INDUSTRI 4.0."

[9] A. S. Putra, "IMPLEMENTASI PERATURAN PERUNDANGAN UU. NO 31 TAHUN 2000 TENTANG DESAIN INDUSTRI BERBASIS INFORMATION TECHNOLOGY."

[10] A. S. Putra, "IMPLEMENTATION OF PARADOX DBASE."

[11] A. S. Putra, "IMPLEMENTATION OF TRADE SECRET CASE STUDY SAMSUNG MOBILE PHONE."

[12] A. S. Putra, "IMPLEMENTATION PATENT FOR APPLICATION WEB BASED CASE STUDI WWW. PUBLIKLAMPUNG. COM."

A. S. Putra, "IMPLEMENTATION SYSTEM FIRST TO INVENT IN DIGITALLY INDUSTRY."

[14] A. S. Putra, "MANUAL REPORT \& INTEGRATED DEVELOPMENT

ENVIRONMENT BORLAND DELPHI 7.0."

[15] A. S. Putra, "PATENT AS RELEVAN SUPPORT RESEARCH."

[16] A. S. Putra, "PATENT FOR RESEARCH STUDY CASE OF APPLE. Inc." 
[17] A. S. Putra, "PATENT PROTECTION FOR APPLICATION INVENT."

[18] A. S. Putra, "QUICK REPORT IN PROPERTY PROGRAMMING."

[19] A. S. Putra, "REVIEW CIRCUIT LAYOUT COMPONENT

REQUIREMENT ON ASUS NOTEBOOK."

[20] A. S. Putra, "REVIEW TRADEMARK PATENT FOR INDUSTRIAL TECHNOLOGY BASED 4.0."

[21] A. S. Putra, "TOOLBAR COMPONENT PALLETTE IN OBJECT ORIENTED PROGRAMMING."

[22] A. S. Putra, "WORKING DIRECTORY SET FOR PARADOX 7."

[23] A. S. Putra, "ZQUERY CONNECTION

IMPLEMENTED

PROGRAMMING

STUDI

CASE PT. BANK BCA Tbk."

[24] A. S. Putra, D. R. Aryanti, and I. Hartati, "Metode SAW (Simple Additive Weighting) sebagai Sistem Pendukung Keputusan Guru Berprestasi (Studi Kasus: SMK Global Surya)," in Prosiding Seminar Nasional Darmajaya, 2018, vol. 1, no. 1, pp. 85-97.

[25] A. S. Putra and O. M. Febriani, "Knowledge Management Online Application in PDAM Lampung Province," in Prosiding International conference on Information Technology and Business (ICITB), 2018, pp. 181-187.

[26] A. S. Putra, O. M. Febriani, and
B. Bachry, "Implementasi Genetic Fuzzy System Untuk Mengidentifikasi Hasil Curian Kendaraan Bermotor Di Polda Lampung," SIMADA (Jurnal Sist. Inf. dan Manaj. Basis Data), vol. 1, no. 1, pp. 21-30, 2018.

[27] A. S. Putra, H. Sukri, and K. Zuhri, "Sistem Monitoring Realtime Jaringan Irigasi Desa (JIDES) Dengan Konsep Jaringan Sensor Nirkabel," IJEIS (Indonesian J. Electron. Instrum. Syst., vol. 8, no. 2, pp. 221-232.

[28] D. P. Sari, O. M. Febriani, and A. S. Putra, "Perancangan Sistem Informasi SDM Berprestasi pada SD Global Surya," in Prosiding Seminar Nasional Darmajaya, 2018, vol. 1, no. 1, pp. 289-294. 